\title{
Further Evidence for a S-Syn Correlation in the Purine( $\beta$ )ribosides: The Solution Conformation of Two Tricyclic Analogs of Adenosine and Guanosine
}

\author{
G. Klimke, H.-D. Lüdemann, \\ Institut für Biophysik und Physikalische Biochemie, Universität Regensburg, \\ Postfach 397, D-8400 Regensburg \\ and L. B. Townsend \\ Division of Medicinal Chemistry College of Pharmacy, University of Michigan, \\ Ann Arbor, Michigan, 48109, USA \\ Z. Naturforsch. 34 c, 653 - 657 (1979); received June 7, 1979 \\ Tricyclic Nucleosides, Conformation, NMR \\ From the analysis of the HRNMR spectra of two tricyclic analogues of adenosine and guanosi- \\ ne, 4,5-diamino-9-( $\beta$-D-ribofuranosyl) pyrimido[5,4-f]pyrrolo[2,3-d]pyrimidine (adenosine-ade- \\ nosine, AA) and 4,7-diamino-9-( $\beta$-D-ribofuranosyl) pyrimido[5,4-f]pyrrolo-[2,3-d] pyrimidin-5- \\ one (adenosine-guanosine, $\mathrm{AG}$ ), dissolved in liquid $\mathrm{ND}_{3}$ the preferred conformations of the ribose \\ moiety are derived in the temperature range between +40 and $-60{ }^{\circ} \mathrm{C}$. The analysis is based \\ on the two state $\mathrm{N} \Leftrightarrow \mathrm{S}$ model of the furanoside ring proposed by Altona and Sundaralingam. \\ - Both compounds show a pronounced stabilization of the S-conformer of the sugar ring $([\mathrm{S}] \sim 0.8)$. \\ The van't Hoff enthalpy for the $\mathrm{S} \Leftrightarrow \mathrm{N}$ equilibrium is $-3 \mathrm{~kJ} \mathrm{~mol}^{-1}$. The syn $\Leftrightarrow$ anti equilibrium \\ is even at $-60^{\circ} \mathrm{C}$ fast compared to the HRNMR time scale.
}

\section{Introduction}

From the analysis of the common purine $(\beta)$ ribosides by HRNMR and NMR relaxation techniques a correlation between the conformation of the furanoside ring and the glycosyl torsion angle could be derived $[1,2]$. In the $\mathrm{N}$-form (C 3 '-endo) of the ribose the glycosyl torsion angle of the base is found in the anti region $\left(180^{\circ} \leqq \mathrm{Y} \leqq 260^{\circ}\right)$, while in the $\mathrm{S}$ conformation of the sugar ( $\mathrm{C} 2^{\prime}$-endo) the base reveals a pronounced preference for the syn range of the glycosyl torsion angle $\left(0 \leqq \mathrm{Y} \leqq 60^{\circ}\right)$. The common pu$\operatorname{rine}(\beta)$ ribosides, however, only show a slight preference for the S-syn conformation, $\mathrm{N}$-anti is with a mole fraction around 0.4 almost equally strong populated. Subsequent studies on 2'- and 3'-deoxyaminoadenosine [3], two compounds showing a pronounced preference for the $\mathrm{S}$ and $\mathrm{N}$ ribose, respectively, confirmed the correlations derived for the natural purine $(\beta)$ ribosides.

\footnotetext{
Abbreviations: A, adenosine; $8 \mathrm{BrA}$, 8-bromoadenosine; AA, 4,5-diamino-9-( $\beta$-D-ribofuranosyl) pyrimido[5,4-f]pyrrolo[2,3-d]pyrimidine (adenosine-adenosine); G, guanosine; $8 \mathrm{BrG}, 8$-bromoguanosine; $\mathrm{AG}, 4,7$-diamino-9-( $\beta$-D-ribofuranosyl) pyrimido [5,4-f]pyrrolo[2,3-d] pyrimidin-5-one.

Reprint requests to Dr. H.-D. Lüdemann.

0341-0382/79/0900-0653 \$01.00/0
}

The two tricyclic analogues of adenosine and guanosine studied here, represent compounds where the base is free to interconvert by $\pm 180^{\circ}$ around the glycosidic bond without changing the interaction with the sugar moiety. The sterical relationships between sugar and base are at all allowed glycosyl torsion angles equal to the geometrical demands of the syn conformation in the purine $(\beta)$ ribosides.

\section{Experimental}

The synthesis of the tricyclic nucleosides adenosineadenosine and adenosine-guanosine has been published previously [4]. $5 \mathrm{mg}$ of each substance were dissolved in $0.5 \mathrm{ml}$ liquid trideuteroammonia. Details of the sample preparation have been given elsewhere [1,2].

The spectra were obtained at $100.1 \mathrm{MHz}$ on a Varian XL-100-15 FT spectrometer equipped with a $16 \mathrm{k}$ 6201-100 computer and disk accessory. The digital resolution of the spectra was $0.1 \mathrm{~Hz}$. Temperatures were measured before and after each experiment with a miniature thermocouple. They are accurate to $\pm 0.5^{\circ} \mathrm{C}$. The analysis of the proton spectra of the ribose moiety was performed by application of the computer program LAME (QCPE no. 111). The simulations were considered successful, if the 
deviation between all resolved lines in the experimental and simulated spectra was $\leqq 0.1 \mathrm{~Hz}$.

Chemical shifts given in Table III are referenced to an external standard of $1 \%$ TMS dissolved in $\mathrm{CS}_{2}$. No attempts to correct for bulk magnetic susceptibility effects were made. The proton longitudinal relaxation measurements were performed with a $180^{\circ}-\tau-90^{\circ}-5 \cdot T_{1}$ pulse sequence of the SYMON program of the disk accessory. Details of the experi-

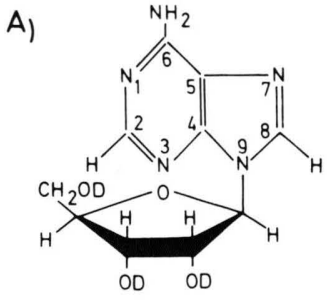

A

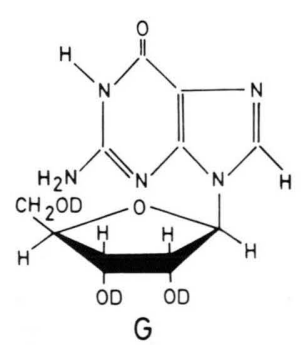

B)

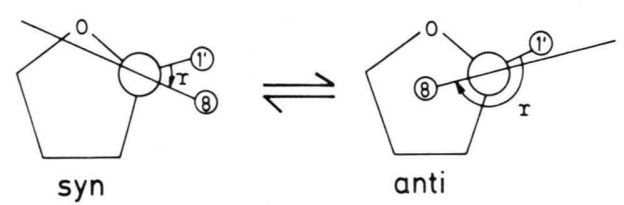

C)

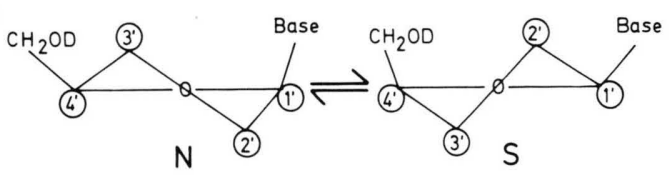

D)

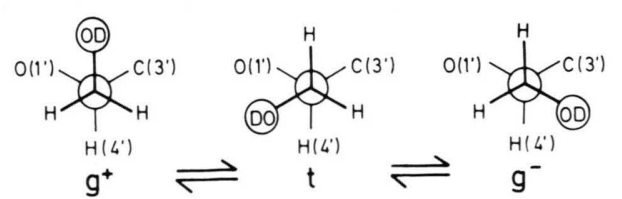

Fig. 1. Structural formulas and possible internal motions of the nucleoside analogs studied: A) chemical structure of $\mathrm{A}, \mathrm{AA}, \mathrm{G}$ and $\mathrm{AG} ; \mathrm{B}$ ) rotation around the glycosidic bond; C) peudorotation of the ribose ring; D) Newmann projection along the $\mathrm{C} 4^{\prime}-\mathrm{C} 5^{\prime}$ bond showing the three classical rotamers. mental procedures have been described elsewhere [1, 2]. The time dependent amplitudes did not show any deviations from a single exponential function for times $\tau \leqq 2 \mathrm{~T}_{1}$.

\section{Theoretical Section}

The sterical flexibility of the nucleoside framework is given by three equilibria (Fig. 1):

1. The rotation around the glycosidic bond: the syn $\Leftrightarrow$ anti equilibrium of the base.

2. The conformational equilibrium of the furanoside ribose ring: The pseudorotation of the ring with the two states of minimum energy $N$ and $S[5,6]$.

3. The rotation of the exocyclic $5^{\prime} \mathrm{CH}_{2} \mathrm{OD}$-group around $\mathrm{C} 4^{\prime}-\mathrm{C} 5^{\prime}$ described by the three rotamers $g^{+}, t$, and $g^{-}[7,8]$.

The equilibria 2. and 3. concern the ribose moiety only and the positions of these equilibria can be derived from an analysis of the vicinal proton proton coupling constants of the ribose protons [5 - 8].

Details of the procedure employed for the $\mathrm{ND}_{3}$ solutions have been published earlier [9].

For the purine $(\beta)$ ribosides the quantitative description of the $s y n \Leftrightarrow$ anti equilibrium could be obtained from the analysis of the proton longitudinal relaxation rates and the intra-molecular NOE factors $[10,1,2]$. The complete longitudinal relaxation rate of a specific proton in a molecule of the size of a nucleoside is given by $[10,11]$ :

$$
R_{i}=\sum_{j \neq i} \varrho_{i j}+\varrho_{i}^{*}
$$

with $\varrho_{i j}$ the direct dipolar relaxation rate given by

$$
\varrho_{i j}=\gamma_{\mathrm{H}}^{4} \hbar^{2} \tau_{\mathrm{c}} r_{i j}^{-6} .
$$

$\gamma_{\mathrm{H}}$ being the gyromagnetic ratio of the proton, $r_{i j}$ the distance between proton $i$ and $j$ and $\tau_{\mathrm{c}}$ the rotational correlation time. The term $\varrho_{i}^{*}$ includes all other intramolecular relaxation paths of spin $i$.

However, because of the $r^{-6}$ dependence, relaxation studies are only applicable, if at least one proton at the base moiety approaches some of the ribose protons to a distance between 0.40 and $0.25 \mathrm{~nm}$. At greater distances the badly defined term $\varrho_{i}^{*}$ becomes the dominating term in Eqn (1) and one cannot extract any geometrical information from the $R_{i}$ studies. 


\section{Results and Discussion}

Relaxation rate studies, position of the syn $\Leftrightarrow$ anti equilibrium

Table I contains the relaxation rates obtained for the single protons of $\mathrm{AA}$ and $\mathrm{AG}$ at $-60{ }^{\circ} \mathrm{C}$ compared with the previously published data for A [1]. In the purine $(\beta)$ ribosides the base proton $\mathrm{H} 8$ is ideally suited for an analysis of the $s y n \Leftrightarrow$ anti equilibrium $[10,1,2]$, while the experimental relaxation rate of $\mathrm{H} 2$ is almost an order of magnitude smaller than the rates of the remaining protons, thus the relaxation of $\mathrm{H} 2$ is dominated by the $\varrho_{2}^{*}$ term. The same holds for the corresponding protons ( 2 and 7$)$ in $\mathrm{AA}$ and $\mathrm{AG}$,

Table I. Longitudinal relaxation rates of the single protons of $\mathrm{A}, \mathrm{AA}$, and $\mathrm{AG}$ in $\mathrm{ND}_{3}$ at $-60^{\circ} \mathrm{C}$.

\begin{tabular}{|c|c|c|c|}
\hline $\begin{array}{l}1 / T_{1} \\
{\left[\mathrm{sec}^{-1}\right]}\end{array}$ & A & $\mathrm{AA}$ & $\mathrm{AG}$ \\
\hline $\begin{array}{l}\text { H } 1^{\prime} \\
\text { H 2' } \\
\text { H 3' } \\
\text { H } 4^{\prime} \\
\text { H 5 }{ }_{\text {A + B }}^{\prime} \\
\text { H 2 } \\
\text { H } 8\end{array}$ & $\begin{array}{l}0.26 \\
0.84 \\
0.91 \\
0.63 \\
2.86 \\
0.0059 \\
0.44\end{array}$ & $\begin{array}{l}0.34 \\
0.80 \\
0.87 \\
0.91 \\
3.3 \\
0.10 \\
-\end{array}$ & $\begin{array}{l}0.32 \\
0.91 \\
0.71 \\
1.0 \\
3.3 \\
0.081 \\
-\end{array}$ \\
\hline
\end{tabular}

the only base protons remaining in the tricyclic analogs. As can be seen from the interproton distances given in Fig. 2 these protons can approach only ${\mathrm{H} 2^{\prime}}^{\prime}$ in a very small region of the glycosyl torsion angle to distances below $0.4 \mathrm{~nm}$ and these ranges of the glycosyl torsion angles are energetically unfavourable because of close contacts between $\mathrm{H}_{2}^{\prime}$ and $\mathrm{N} 3$, respectively $\mathrm{N} 1$ or $\mathrm{N} 7$ in the tricyclic analogs.

It is thus impossible to derive from the relaxation studies the position of the $s y n \Leftrightarrow$ anti equilibrium.

The base proton signals in AA and AG remain sharp down to the lowest temperature, and also the sugar moiety reveals, compared to A sharp signals down to the lowest temperatures reached. The chemical shifts (Table III) of $\mathrm{H} 2$ (H 7), $\mathrm{H}^{\prime}$ and $\mathrm{H}^{\prime}$ in $\mathrm{AA}$ and $\mathrm{AG}$ differ at the lowest temperature by up to $0.15 \mathrm{ppm}$ and one can consequently expect, that these signals should become broadened and finally separated, if the rate of the syn $\Leftrightarrow$ anti conversion becomes comparable to the chemical shift difference. This result is in marked contrast to the behaviour of the pteridinenucleosides [12], in these compounds the sugar signals broaden at temperatures below $0{ }^{\circ} \mathrm{C}$ and at $-60{ }^{\circ} \mathrm{C}$ two resolved multipletts are

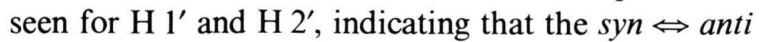

inversion in these compounds is slow on the time scale of a HRNMR experiment. The sharp signals found in the tricyclic analogs and especially the fact that only one signal is found for $\mathrm{H} 2$ and $\mathrm{H} 7$ in $\mathrm{AA}$, can thus tentatively be taken as evidence that the activation energy for the $s y n \Leftrightarrow a n t i$ inversion for these compounds is considerably lower than the activation energy of $\sim 40 \mathrm{~kJ} \mathrm{~mol}^{-1}$ found for the furanoside pteridinenucleosides [13].

\section{$H R N M R$ studies, conformation of the ribose moiety}

The results of the analysis of the proton spectra are contained in Tables II and III. In both substances $\mathrm{J}_{1^{\prime} 2^{\prime}}$ increases and $\mathrm{J}_{3^{\prime} 4^{\prime}}$ decreases with falling temperature. The only significant difference between AA and $A G$ is found in $\mathrm{J}_{4^{\prime}} 5^{\prime} \mathrm{A}+\mathrm{B}$. In AG these coupling constants are significantly smaller than the corresponding results observed in AA.

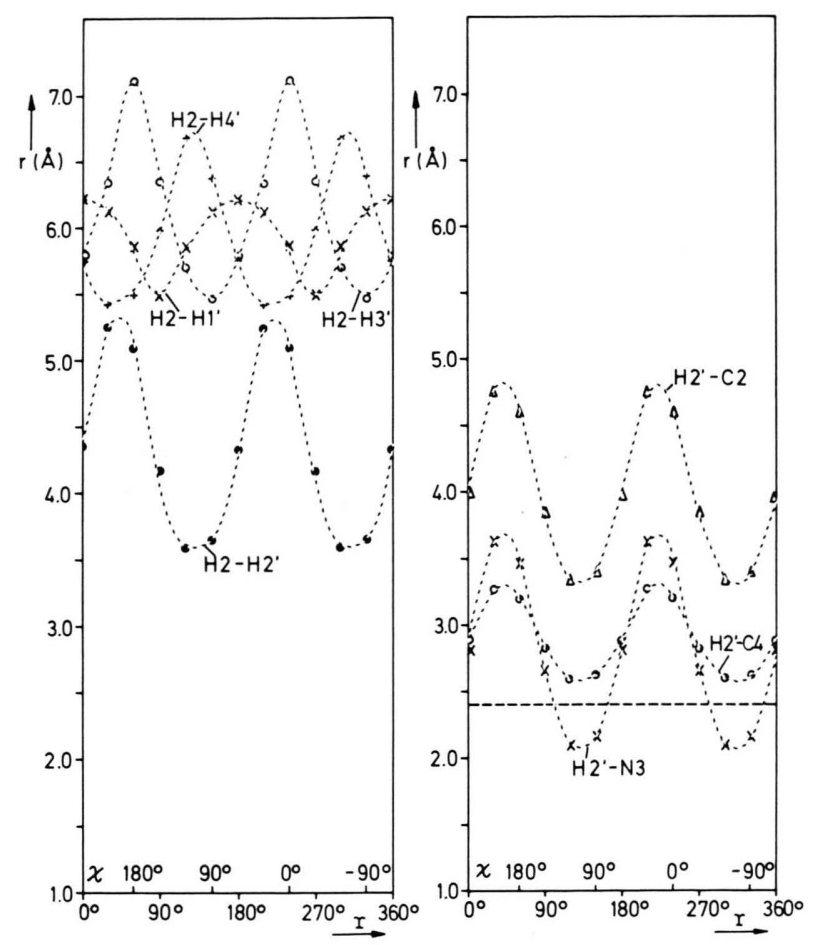

Fig. 2. a) Distances between the base proton $\mathrm{H} 2$ and the four ribose ring protons $\mathrm{H}^{\prime}$ to $\mathrm{H}^{\prime}$ as a function of the glycosyl torsion angle $\mathrm{Y}(\chi)$. b) Distances between the ribose ring proton $\mathrm{H}_{2}^{\prime}$ and some base atoms as function of the glycosyl torsion angle $\mathrm{Y}(\chi)$. The dotted line indicates the van-der-Waals' contact distances of $\mathrm{N} \ldots \mathrm{H}$ and $\mathrm{C} \ldots \mathrm{H}$. Both figures show the case of the symmetric AA. The data are derived from the interatomic distances calculated for adenosine. In the tricyclic analogs $\mathrm{N} 3$ of the purine rings corresponds to $\mathrm{N} 1$ and $\mathrm{N} 8$ while $\mathrm{C} 2$ corresponds to $\mathrm{C} 2$ and $\mathrm{C} 7$. 


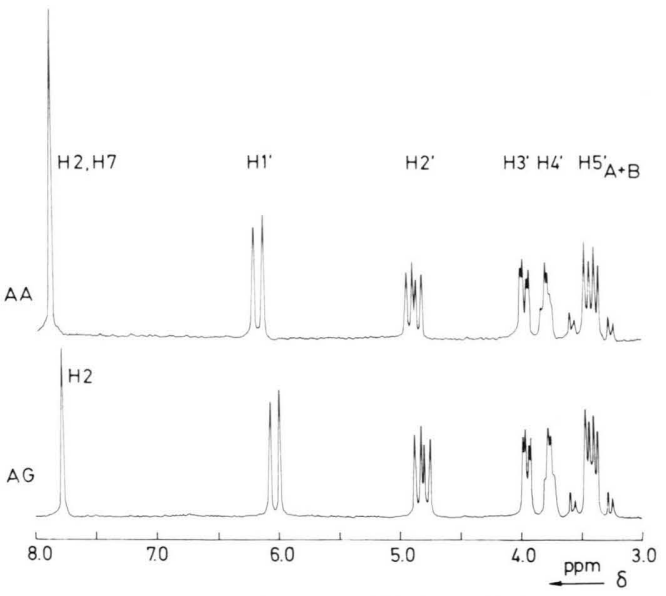

Fig. 3. Experimental proton high resolution spectra of solutions of $\mathrm{AA}$ and $\mathrm{AG}$ in $\mathrm{ND}_{3}$ at $-60^{\circ} \mathrm{C}$.

Table II. Vicinal proton proton coupling constants of the ribose protons in $\mathrm{Hz}$ of the two tricyclic compounds dissolved in $\mathrm{ND}_{3}$ at $+40{ }^{\circ} \mathrm{C}$ and $-60{ }^{\circ} \mathrm{C}$.

\begin{tabular}{llllll}
\hline$J_{\mathrm{ij}}[\mathrm{Hz}]$ & $\mathrm{AA}$ & & & \multicolumn{2}{c}{$\mathrm{AG}$} \\
\cline { 2 - 3 } \cline { 5 - 6 }$T\left[{ }^{\circ} \mathrm{C}\right]$ & +40 & -60 & & +40 & -60 \\
\hline$J_{1^{\prime} 2^{\prime}}$ & 6.8 & 7.7 & & 7.1 & 7.7 \\
$J_{2^{\prime} 3^{\prime}}$ & 5.4 & 5.1 & & 5.4 & 5.0 \\
$J_{3^{\prime} 4^{\prime}}$ & 2.9 & 1.8 & & 2.4 & 1.7 \\
$J_{4^{\prime} 5^{\prime} \mathrm{A}}$ & 3.5 & 3.6 & & 2.8 & 3.2 \\
$J_{4^{\prime} 5^{\prime} \mathrm{B}}$ & 4.6 & 3.9 & & 3.7 & 3.5 \\
\hline
\end{tabular}

From the coupling constants the populations of the different conformers are derived. These data are shown together with previously published results [1, 9] for $\mathrm{A}, \mathrm{G}, 8 \mathrm{BrA}$ and $8 \mathrm{BrG}$ in Table IV. In both $\mathrm{AA}$ and $\mathrm{AG}$ the S-conformer is dominating. It can be seen that the two compounds behave very similar to the 8-bromo substituted purine $(\beta)$ nucleosides. The position of the $\mathrm{N} \Leftrightarrow \mathrm{S}$ equilibrium is within the accuracy of the analysis identical in $8 \mathrm{BrA}$ and AA, while the stabilization of the S-ribose is marginally more pronounced in $8 \mathrm{BrG}$ as compared to AG. In our opinion this latter difference is an additional hint that both conformers of AG, with the adenine part respectively the guanine in the syn range are populated with comparable mole fractions.

The $g^{+}$conformer, with the 5'-hydroxyl group above the furanoside ring in greatest proximity to the base moiety, is under all conditions the dominant conformer.

Compared to the purine $(\beta)$ ribosides the tricyclic compounds AA and AG have to be regarded as pure syn nucleosides, since in all possible ranges of the glycosyl torsion angle they have one of the two pyrimidine rings above the ribose ring. These compounds thus confirm a correlation between the syn position of the base and the $\mathrm{S}$ state of the ribose previously derived for the purine $(\beta)$ ribosides $[1-3]$. The same correlation appears to hold also for the

Table III. Chemical shifts of the single protons of AA, AG, A and G dissolved in $\mathrm{ND}_{3}$ at $+40{ }^{\circ} \mathrm{C}$ and $-60^{\circ} \mathrm{C}$.

\begin{tabular}{|c|c|c|c|c|c|c|c|c|}
\hline \multirow{2}{*}{$\begin{array}{c}\delta[\mathrm{ppm}] \\
T\left[{ }^{\circ} \mathrm{C}\right]\end{array}$} & \multicolumn{2}{|l|}{ A } & \multicolumn{2}{|l|}{ AA } & \multicolumn{2}{|l|}{ G } & \multicolumn{2}{|l|}{$\mathrm{AG}$} \\
\hline & +40 & -60 & +40 & -60 & +40 & -60 & +40 & -60 \\
\hline $\mathrm{H} \mathrm{l}^{\prime}$ & 5.63 & 5.67 & 6.143 & 6.147 & 5.36 & 5.44 & 5.935 & 6.020 \\
\hline $\mathrm{H} 2^{\prime}$ & 4.15 & 4.14 & 4.802 & 4.864 & 4.08 & 4.05 & 4.705 & 4.803 \\
\hline $\mathrm{H} 3^{\prime}$ & 3.86 & 3.87 & 3.949 & 3.954 & 3.78 & 3.82 & 3.905 & 3.945 \\
\hline $\mathrm{H} 4^{\prime}$ & 3.67 & 3.71 & 3.666 & 3.774 & 3.58 & 3.64 & 3.638 & 3.758 \\
\hline $\mathrm{H} 5^{\prime} \mathrm{A}$ & 3.39 & 3.40 & 3.396 & 3.485 & 3.31 & 3.37 & 3.387 & 3.490 \\
\hline $\mathrm{H} 5^{\prime} \mathrm{B}$ & 3.28 & 3.29 & 3.257 & 3.327 & 3.20 & 3.25 & 3.247 & 3.346 \\
\hline H 2 & 7.88 & 7.84 & & & & & & \\
\hline H 8 & 8.08 & 8.27 & & & 7.37 & 7.57 & & \\
\hline
\end{tabular}

Table IV. Results of the conformational analysis for the two tricyclic compounds compared to A, $8 \mathrm{BrA}, \mathrm{G}$ and $8 \mathrm{BrG}$.

\begin{tabular}{|c|c|c|c|c|c|c|c|c|c|c|c|c|}
\hline \multirow[b]{2}{*}{$T\left[{ }^{\circ} \mathrm{C}\right]$} & \multicolumn{2}{|l|}{ A } & \multicolumn{2}{|l|}{$8 \mathrm{BrA}$} & \multicolumn{2}{|l|}{$\mathrm{AA}$} & \multicolumn{2}{|l|}{ G } & \multicolumn{2}{|l|}{$8 \mathrm{BrG}$} & \multicolumn{2}{|l|}{$\mathrm{AG}$} \\
\hline & +40 & -60 & +40 & -60 & +40 & -60 & +40 & -60 & +40 & -60 & +40 & -60 \\
\hline $\begin{array}{l}{[\mathrm{N}]} \\
{\left[\mathrm{g}^{+}\right]} \\
{[\mathrm{t}]}\end{array}$ & $\begin{array}{l}0.45 \\
0.68 \\
0.15\end{array}$ & $\begin{array}{l}0.43 \\
0.70 \\
0.20\end{array}$ & $\begin{array}{l}0.28 \\
0.45 \\
0.26\end{array}$ & $\begin{array}{l}0.17 \\
0.22 \\
0.47\end{array}$ & $\begin{array}{l}0.27 \\
0.55 \\
0.16\end{array}$ & $\begin{array}{l}0.18 \\
0.62 \\
0.17\end{array}$ & $\begin{array}{l}0.40 \\
0.73 \\
0.13\end{array}$ & $\begin{array}{l}0.37 \\
0.75 \\
0.14\end{array}$ & $\begin{array}{l}0.21 \\
0.70 \\
0.14\end{array}$ & $\begin{array}{l}0.12 \\
0.72 \\
0.14\end{array}$ & $\begin{array}{l}0.25 \\
0.73 \\
0.08\end{array}$ & $\begin{array}{l}0.18 \\
0.71 \\
0.13\end{array}$ \\
\hline
\end{tabular}




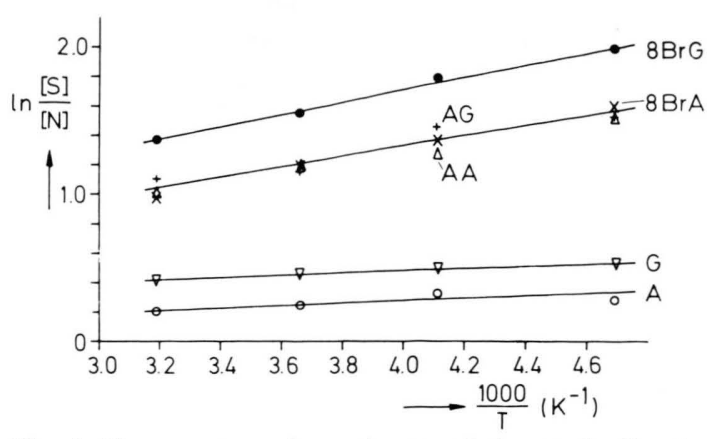

Fig. 4. Temperature dependence of the mole fraction in the $\mathrm{S}$ and $\mathrm{N}$ state of $\mathrm{AA}$ and $\mathrm{AG}$, compared to $\mathrm{A}, 8 \mathrm{BrA}, \mathrm{G}$ and $8 \mathrm{BrG}$.

5 -adenosinemonophosphatemonomethylester, a natural $5^{\prime}$-purine $(\beta)$ nucleotide analogue $[14,15]$.

It must, however, be stated, that this correlation was only derived and thoroughly tested for purine $(\beta)$ nucleosides and analogues with similar geometrical constraints. In these substances a correlation between S-syn and N-anti could be derived. It is not to be expected that these correlations should also hold for the pyrimidine $(\beta)$ nucleosides and -nucleotides including their analogues [16].

In Fig. 4 the temperature dependence of the position of the $\mathrm{N} \Leftrightarrow \mathrm{S}$ equilibrium is shown in a van't

[1] H.-D. Lüdemann, O. Röder, E. Westhof, E. v. Goldammer, and A. Müller, Biophys. Struct. Mechanism 1, $121-137(1975)$.

[2] H.-D. Lüdemann, E. Westhof, and O. Röder, Eur. J. Biochem. 49, 143 - 150 (1974).

[3] H. Plach, E. Westhof, H.-D. Lüdemann, and R. Mengel, Eur. J. Biochem. 80,295 - 304 (1977).

[4] J. L. Chung, K. H. Schram, R. P. Ponzica, R. A. Earl, L. L. Wotring, and L. B. Townsend, J. Med. Chem., (1979) in press.

[5] C. Altona and M. Sundaralingam, J. Am. Chem. Soc. 94, $8205-8212$ (1972).

[6] C. Altona and M. Sundaralingam, J. Am. Chem. Soc. 95, 2333 - 2344 (1973)

[7] F. E. Hruska, The Jerusalem Symposia on Quantum Chemistry, and Biochemistry. Conformation of Biological Molecules and Polymers (eds. E. D. Bergmann and B. Pullman), Vol. V, pp. $345-360$, Academic Press, New York 1973.

[8] F. E. Hruska, A. Mak, H. Singh, and D. Shugar, Can. J. Chem. 51, 1099 (1973).
Hoff plot. For comparison also the previously published data on $\mathrm{A}, \mathrm{G}, 8 \mathrm{BrA}$, and $8 \mathrm{BrG}$ are given. The minute differences in the $[\mathrm{S}] /[\mathrm{N}]$ ratios for $\mathrm{AA}$ and $\mathrm{AG}$ as compared to the more pronounced changes in $8 \mathrm{BrA}$ and $8 \mathrm{BrG}$ could possibly be explained by a slight preference of AG to adopt the "syn-adenosine" conformation, with the 7-amino group completely exposed to the polar environment of the solvent molecules. A van't Hoff enthalpy of -3 $\mathrm{kJ} \mathrm{mol}^{-1}$ is derived for the stabilization of the S-conformer for all purine $(\beta)$ nucleoside analogues constrained to the syn-position of the base.

The line through the results for $8 \mathrm{BrG}$ as well as the line through the data for $8 \mathrm{BrA}$, $\mathrm{AA}$ and $\mathrm{AG}$ intercept for $T \rightarrow \infty$ the origin of the diagram. This is a further strong evidence for the validity of the description of the conformational flexibility of the furanoside ring in the two state $\mathrm{N} \Leftrightarrow \mathrm{S}$ model.

\section{Acknowledgements}

Financial support by the Deutsche Forschungsgemeinschaft and by the Fonds der Chemischen Industrie is gratefully acknowledged. G. Klimke received a scholarship from the Friedrich-Ebert-Stiftung.

[9] E. Westhof, O. Röder, I. Croneiss, and H.-D. Lüdemann, Z. Naturforsch. 30 c, 131 - 140 (1975).

[10] R. E. Schirmer, J. P. Davies, J. H. Noggle, and P. A. Hart, J. Am. Chem. Soc. 94, 2561 - 2572 (1972).

[11] J. H. Noggle and R. E. Schirmer, The Nuclear Overhauser Effect. Chemical Applications, Academic Press, New York 1971.

[12] H. v. Voithenberg, A. Skrzelewski, J. C. Jochims, and W. Pfleiderer, Tetrahedron Lett. 4063 - 4066 (1974).

[13] J. C. Jochims, W. Pfleiderer, K. Kobayashi, G. Ritzmann, and W. Hutzenlaub, Chem. Ber. 106, 2975 (1973).

[14] H.-D. Lüdemann and E. Westhof, Nuclear Magnetic Resonance Spectroscopy in Molecular Biology (ed. B. Pullman) pp. $41-55$, Reidel Publish. Comp. Dordrecht 1978.

[15] H. Plach, Dr.-Thesis, Universität Regensburg, 1978.

[16] J. M. Neumann, J. Borrel, J. M. Thiery, W. Guschlbauer, and S. Tran-Dinh, Biochim. et Biophys. Acta, 479, 427 - 440 (1977). 